\title{
Overexpression of Capsular Polysaccharide Biosynthesis Protein in Lactobacillus plantarum P1 to Enhance Capsular Polysaccharide Production for Di-n-butyl Phthalate Adsorption
}

\author{
Wei-Bing Liu ${ }^{\dagger}$, Zhi-Wei Lin ${ }^{\dagger}$, Ying Zhou* ${ }^{*}$, and Bang-Ce Ye* \\ Lab of Biosystems and Microanalysis, Biomedical Nanotechnology Center, State Key Laboratory of Bioreactor \\ Engineering, East China University of Science and Technology, Shanghai 200237, P.R. China
}

\begin{abstract}
Exopolysaccharides (EPSs) such as capsular polysaccharide (CPS) are important bioactive carbohydrate compounds and are often used as bioenrichment agents and bioabsorbers to remove environmental pollutants like di-n-butyl phthalate (DBP). Among the EPS-producing bacteria, lactic acid bacteria (LAB) have gained the most attention. As generally recognized as safe (GRAS) microorganisms, LAB can produce EPSs having many different structures and no health risks. However, EPS production by LAB does not meet the needs of large-scale application on an industrial scale. Here, the capA gene (encoding CPS biosynthesis protein) was overexpressed in Lactobacillus plantarum $\mathrm{P} 1$ to improve the production of EPSs and further enhance the DBP adsorption capability. Compared with P1, the CPS production in capA overexpressed strain was increased by $11.3 \mathrm{mg} / \mathrm{l}$, and the EPS thickness was increased from $0.0786 \pm 0.0224 \mu \mathrm{m}$ in $\mathrm{P} 1$ to $0.1160 \pm 0.0480 \mu \mathrm{m}$ in P1-capA. These increases caused the DBP adsorption ratio of P1-capA to be doubled. Overall, the findings in this study provide a safe method for the adsorption and removal of DBP.
\end{abstract}

Keywords: Lactobacillus plantarum, exopolysaccharides, probiotics, overexpression, di-n-butyl phthalate, adsorption

Received: January 21, 2021 Accepted: April 8, 2021

First published online: April 9, 2021

${ }^{*}$ Corresponding authors Y. Zhou

E-mail: zhouying@ecust.edu.cn

B.-C. Ye

Phone: +86-21-64253832

E-mail: bcye@ecust.edu.cn

${ }^{\dagger}$ These authors contributed equally to this work.

pISSN 1017-7825

elSSN 1738-8872

Copyright $@ 2021$ by the authors. Licensee KMB. This article is an open access article distributed under the terms and conditions of the Creative Commons Attribution (CC BY) license

\section{Introduction}

Exopolysaccharide (EPSs) are known as carbohydrate polymers with high molecular weight, and are composed of monosaccharide residues. Generally, EPSs are in the cell wall through extracellular in situ synthesis or secreted into the extracellular environment and play various vital roles due to their biocompatibility and non-toxicity. EPSs are often used as bioenrichment agents, bioabsorbers, heavy metal removers, and drug delivery agents in biology and medicine [1]. In addition, EPSs also possess excellent viscosity and rheology and have been explored for application in the dairy industry. So far, many studies have shown that EPSs can be produced by plants, algae, and fungi as well as bacteria [2]. Among bacteria, lactic acid bacteria (LAB) have been widely used to produce EPSs to prolong the shelf-life of fermentation food and retain its flavor because of the ability of EPSs in impacting viscosity, syneresis and sensory properties [3-5]. LAB are generally recognized as safe (GRAS) microorganisms in food. Therefore, LAB are well suited for producing EPSs for adsorbing and removing environmental pollutants, and several previous works have demonstrated that $\mathrm{LAB}$ can eliminate tenuazonic acid, acrylamide, or mycotoxin in vivo or in vitro [6-8]. However, the EPS production of LAB does not meet the needs large-scale application in industry. The rapid development of molecular biological technology has served to elucidate the biosynthesis pathway of EPSs. The use of genetic engineering methods is an important way to increase the production of EPSs in lactobacillus. In addition, researchers have analyzed the enzymes related to EPS production in lactobacillus and found that the activities of UDP-galactose-4-epimerase, $a$-phosphoglucomutase and UDP-glucose pyrophosphorylase are important in the cell extract [9]. Boels et al. overexpressed the whole gene cluster related to the synthesis of EPSs in Lactococcus, which could enhance the production of EPSs by four times to $345 \mathrm{mg} / \mathrm{l}$. Boels et al. modified Lactococcus lactis by metabolic engineering to alter the carbon distribution between glycolysis and nucleotide sugar biosynthesis, thus increasing the intracellular levels of UDP-glucose, UDP-galactose and UDPrhamnosus, and increasing EPS production [10].

The synthesis of EPSs is a quite complex biological process, involving a variety of enzymes and regulatory proteins $[11,12]$. It contains four major steps: sugar transportation, synthesis of sugar-1p, polymerization of 


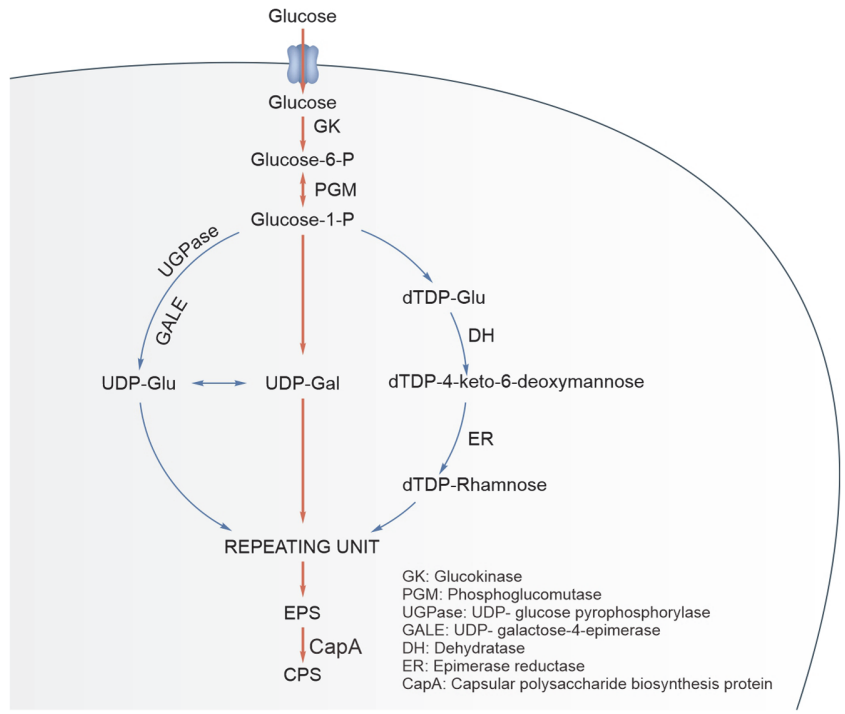

Fig. 1. The biosynthetic pathway of CPS.

repeating units, and EPS exportation [13]. Some EPSs can be categorized as capsular polysaccharides (CPS), which are covalently bound to the outer cell membrane (Fig. 1). Another type are called slime polysaccharides (SPS), which are released from the cell wall $[14,15]$. CPS biosynthesis protein (CapA) is required for the biosynthesis of type I CPS [16]. This protein is involved in the biosynthesis pathway of CPS, and is concerned with capsule biogenesis and is essential for high-level polymerization. Beyond these works, there have been few studies on the CPS production of LAB, therefore, research on increasing the yield of CPS will be helpful for the application of LAB in the absorption and removal of toxins such as di-n-butyl phthalate (DBP from the human body).

DBP is widely used in many daily plastic products as a plasticizer for packaging material for food, personal toiletries, and plastic toys [17]. Furthermore, evidence has shown that DBP can damage the genital system and behavior of human beings and wildlife with long-term exposure, and even at very low dose [18-20]. Within natural the environment, the removal of DBP mainly relies on microbial adsorption and degradation [21].

In a previous work, we studied the feasibility of DBP adsorption by LAB [22]. Here, we aimed to increase the CPS production of $L$. plantarum P1, and explored how to enhance the function of DBP adsorption in LAB. First, the vector pMG36e [23] is an effective tool for genetic engineering of LAB. The ability whereby pMG36e constitutively expresses an inserted gene in LAB indicated that it could be modified to generate the novel foodgrade expression vector based on it [24]. Many studies have proved that the vector pMG36e is an effective expression vector for genetic engineering of LAB [25-30], so the lactobacillus universal plasmid pMG36e is used to overexpress the CPS biosynthesis protein (CapA), the endogenous gene of L. plantarum P1. In addition, some previous works demonstrated that LAB could bind to DBP [31,32]. In our study we investigated the effects of capA overexpression on DBP adsorption. This work may help extend the application of LAB in eliminating DBP from the environment.

\section{Materials and Methods}

\section{Bacterial Culture and Plasmid Purification}

The strains and plasmids used in this study are listed in Table 1. L. plantarum P1 was cultured in MRS broth (Solarbio Co., China) at $30^{\circ} \mathrm{C}$ for $24 \mathrm{~h}$. Chemically competent Escherichia coli (E. coli) DH5a (TransGen Biotech, China) was used for recombinant construction. Cells were cultivated on $90 \mathrm{~mm}$ disks with Luria-Bertani (LB) medium at $37^{\circ} \mathrm{C}$. Erythromycin was used as a selection marker during cloning. For the selection of erythromycinresistant E. coli DH5a and L. plantarum P1 strains after transformation, either $600 \mu \mathrm{g} / \mathrm{ml}$ or $2.5 \mu \mathrm{g} / \mathrm{ml}$ of

Table 1. Bacterial strains, plasmids and primers used in this study.

\begin{tabular}{ll}
\hline Strains and plasmids & \multicolumn{1}{c}{ Resource } \\
\hline Escherichia coli DH5a & Purchased from TransGen Biotech (Beijing) Co., Ltd. \\
L.plantarum $\mathrm{P} 1$ & lab stock (isolated from Chinese traditional fermented food Naipizi) \\
pMG36e & lab stock \\
pMG36e-flag-capA & This study \\
capA-F1 & This study \\
capA-R1 & This study \\
capA-F2 & This study \\
capA-R2 & This study \\
\hline
\end{tabular}


erythromycin was used. Plasmids in E. coli were purified with an EasyPure Plasmid MiniPrep Kit (Beijing TransGen Biotech Co., Ltd.) according to the instructions with the kit.

\section{Construction of the Recombinant Plasmid pMG36e-Flag-capA}

Polymerase chain reactions (PCR) were performed in a PCR thermal cycler (Bio-Rad, USA) with $50 \mu$ of reaction mixture containing the template $(1 \mu \mathrm{l})$, each primer $(2 \mu \mathrm{l})$, polymerase $(1 \mu \mathrm{l})$, dNTP $(1 \mu \mathrm{l})$, deionized water $(18 \mu \mathrm{l})$, and $10 \times$ buffer $(25 \mu \mathrm{l})$. The PCR was run following this program: pre-denaturation at $95^{\circ} \mathrm{C}$ for $5 \mathrm{~min}$, followed by 30 cycles of denaturation at $95^{\circ} \mathrm{C}$ for $15 \mathrm{sec}$; annealing at $57^{\circ} \mathrm{C}$ for $1 \mathrm{~min}$ and extension at $72^{\circ} \mathrm{C}$ for $1 \mathrm{~min}$.

The flag-capA gene was cloned by PCR using specific primers capA-F1/capA-R1 (capA-F1:5'-AAGGACGAC GATGACAAGGATCAAGCAGTAAGTTTTGACTTTTTTATCCGG-3' and capA-R1:5'-TTCAGACTTTGC AAGCTTCTAAACTCGTTTCATCGCTTGTGACG-3') (Table 1). The PCR fragment containing flag-capA gene was cloned into vector pMG36e to generate new plasmid pMG36e-flag-capA. The new resultant plasmid was transformed into L. plantarum P1 by electroporation at $1.25 \mathrm{kV} / \mathrm{cm}$ in a Bio-Rad GenePulser, and then the cells were diluted with $400 \mu \mathrm{l}$ of regeneration medium MRS. The competent cells of $L$. plantarum P1 were prepared following the protocol below. L. plantarum $\mathrm{P} 1$ cells were cultured in MRS at $30^{\circ} \mathrm{C}$ overnight. A total of $50 \mathrm{~mL}$ MRS with $1 \%$ glycine and $0.75 \mathrm{M}$ sorbitol was inoculated with $1 \%$ of the overnight culture. At $\mathrm{OD}_{600}$ of 0.3 , the cells were harvested by centrifugation at $6,000 \times g$, and then washed by sterile water for three times and stored in $1 / 12530 \%$ PEG3000 [33].

\section{Reverse Transcription Quantitative Real-Time PCR Analysis}

Total RNA from recombinant L. plantarum P1 strains was isolated and purified by using the RNA Prep Pure Cell/Bacteria Kit (Tiangen, China). The completeness of the RNA was verified by $1.0 \%$ of agarose gel electrophoresis with a microplate reader. Total RNA $(1 \mu \mathrm{g})$ was reversely transcribed using the PrimeScript RT Reagent Kit with gDNA Eraser (TaKaRa, Japan). Genomic DNA was removed by digestion with DNase for $5 \mathrm{~min}$ at $42^{\circ} \mathrm{C}$. RT-qPCR was performed using a SYBR Premix Ex Taq GC kit with a template cDNA of $75 \mathrm{ng}$ in a CFX96 real-time PCR instrument. Primers listed in Table 1(capA-F2/capA-R2) were used. The reaction conditions were: $95^{\circ} \mathrm{C}, 10 \mathrm{~min}$, then $95^{\circ} \mathrm{C}, 10 \mathrm{~s}, 60^{\circ} \mathrm{C}, 10 \mathrm{~s}$ for 39 cycles, and finally $72^{\circ} \mathrm{C}, 30 \mathrm{~s}$. The internal reference gene is $16 \mathrm{~S}$ rRNA. All samples were prepared in triplicate to obtain the $\mathrm{C}_{\mathrm{T}}$ values, and the relative gene expression levels for each mutant (compared with WT levels) were calculated using the comparative $\mathrm{C}_{\mathrm{T}}$ method $\left(2^{-\Delta \Delta \mathrm{Ct}}\right)$ [34].

\section{Western Blot Analysis}

The P1 mutants were cultured in MRS medium containing erythromycin for $24 \mathrm{~h}$ to make the protein fully expressed. After lysozyme treatment, it was sonicated to obtain the crude enzyme of extracellular polysaccharide synthesis protein.

L. plantarum P1 cell pellets were resuspended in phosphate-buffered saline and subjected to ultrasound breaking, then they were diluted in $6 \times$ protein loading buffer (Trans Biotech, China) and heated for $5 \mathrm{~min}$. Samples were run on a $10 \%$ sodium dodecyl sulfate polyacrylamide gel at $110 \mathrm{~V}$ in Tris-glycine buffers. Gels were then transferred to polyvinylidene difluoride membranes which were incubated with primary antibodies in TBS$\mathrm{T}$ (TBS $0.1 \%$ Tween 20 ) for $12 \mathrm{~h}$ at $4^{\circ} \mathrm{C}$. Next, the membranes were washed three times in TBS-T and incubated for $1 \mathrm{~h}$ with antigoat IgG conjugated with horseradish peroxidase (HRP, Cell Signaling) at a 1/5000 dilution in TBS-T. Finally, the membranes were washed three times in TBS-T and the HRP signal was detected.

\section{Growth Analysis and CPS Production}

L. plantarum $\mathrm{P} 1$ and its mutants were grown in MRS at $30^{\circ} \mathrm{C}$, and in triplicate $50 \mathrm{ml}$ cultures. Growth was analyzed using a microplate reader (BioTek Instruments, USA). Cell density measurements at $\mathrm{OD}_{600}$ were acquired every $4 \mathrm{~h}$. To evaluate CPS production, phenol-sulfuric acid method was used [35]. The bacterial solution was obtained through activation culture, and the cells were obtained by centrifugation. The cells were washed once with physiological saline. Then, the cells were suspended in a glycine buffer $(0.1 \mathrm{M}, \mathrm{pH} 9.2)$, and 100 $\mathrm{mg}$ of lysozyme and $0.02 \%$ of sodium azide was added to inhibit the growth of bacteria, followed by shaking at $37^{\circ} \mathrm{C}$ for $7 \mathrm{~h}$ and centrifuging $(8,000 \mathrm{rpm}, 10 \mathrm{~min})$ to remove the bacterial residue precipitation. $0.1 \mathrm{M} \mathrm{CaCl}_{2}$ was added to the supernatant, shaking for $1 \mathrm{~h}$, and then adding $25 \%(\mathrm{v} / \mathrm{v})$ of absolute ethanol. The samples were placed at $4^{\circ} \mathrm{C}$ for $2 \mathrm{~h}$ and centrifuged $(8,000 \times g, 10 \mathrm{~min})$ to remove the precipitate, and absolute ethanol was added to a final concentration of $80 \%(\mathrm{v} / \mathrm{v})$. The samples were then left at $4^{\circ} \mathrm{C}$ overnight to precipitate, and centrifuged to obtain crude CPS.

To evaluate the CPS titer, a standard curve was drawn with the value of $\mathrm{OD}_{490}$ of glucose as ordinate and the value of concentration $(\mathrm{g} / \mathrm{ml})$ as abscissa. The $\mathrm{OD}_{490}$ and concentration of glucose have a good linear relationship; the linear regression equation is $y=0.0097 x+0.0689\left(R^{2}=0.99845\right)$, and the changes of CPS content in the two strains after culturing for $64 \mathrm{~h}$ were calculated according to this equation.

\section{Observation of EPSs}

The CPS bound to the cell wall, which could be observed by transmission electron microscopy [36]. So, the activated culture was centrifuged at 4,000 $\times g$ for $10 \mathrm{~min}$, washed twice with PBS ( $\mathrm{pH} 7.4$ ), suspended in PBS (pH 7.4), and diluted to an $\mathrm{OD}_{600}$ of $0.3-0.4$. Then, $20 \mu \mathrm{l}$ of that was dropped on a copper mesh. This was left for $20 \mathrm{~min}$ the droplets were sucked up with filter paper, and then the copper mesh was placed on a transmission electron microscope for observation. 
DBP Adsorption Evaluation

To evaluate the DBP adsorption capacity of $L$. plantarum $\mathrm{P} 1$ and its mutants, we tested the DBP $(>99.0 \%, \mathrm{D} \& \mathrm{~B}$ Chemical Technology Co. Ltd., China) adsorption capacity of the strains. Two strains were inoculated from cryopreserved stocks and incubated at $30^{\circ} \mathrm{C}$ for $24 \mathrm{~h}$. The cultures were harvested by centrifugation $(8,000 \times g$, $10 \mathrm{~min}, 4^{\circ} \mathrm{C}$ ), washed twice and resuspended to achieve a density of $2 \times 10^{11}$ colony-forming units $(\mathrm{CFU}) / \mathrm{ml}$ using either normal saline $(0.9 \% \mathrm{NaCl} \mathrm{w} / \mathrm{v})$ or DBP solution $(10 \mathrm{mg} / \mathrm{ml})$. The samples were incubated at $37^{\circ} \mathrm{C}$ for $2 \mathrm{~h}$ without shaking. After incubation, the suspension was centrifuged $(4,000 \times g, 5 \mathrm{~min})$ at room temperature, and the supernatant was extracted by ethyl acetate for the analysis of residual DBP contents. After the extraction, $200 \mu \mathrm{l}$ of supernatant was transferred to a 5-ml glass bottle, and then washed with $1 \mathrm{ml}$ of methyl alcohol. The eluent was collected and filtered through a 0.22 - $\mu \mathrm{m}$ membrane filter, and this was followed by high-performance liquid chromatography (HPLC) analysis to measure unbound DBP. The chromatographic separation was performed on a C18 column $(250 \times 4.6 \mathrm{~mm}$ I.D., $5 \mu \mathrm{m}$; Teknokroma, Spain $)$. The mobile phase for detecting DBP was methanol: water $(80: 20, \mathrm{v} / \mathrm{v})$, the flow rate was $1 \mathrm{ml} / \mathrm{min}$, and UV detection was done at $225 \mathrm{~nm}$. All the assays were conducted in triplicate, and average values were used for data analysis. The adsorption rate of DBP was calculated as follows: adsorption rate $=(10-\mathrm{C} 1) / 10 \times 100 \%(\mathrm{C} 1$ : the concentration of DBP in methanol).

\section{Results}

Construction of the Vector pMG36e-Flag-capA

To overexpress capA gene, the plasmid pMG36e-flag-capA was constructed and transformed into P1 strain, which was then validated by $16 \mathrm{~S}$ rRNA gene sequecning. The recombinant strain was treated by lysozyme and sonication for extracting extracellular polysaccharide synthesis protein, in which, supernatant was collected for western blot characterization. In silico analysis indicated that the protein size of CapA is $30.7 \mathrm{kDa}$ with 256 amino acids. As shown in Fig. 2A, positive bands of CapA were observed in whole protein and supernatant samples, while no target proteins were found in P1-pMG36e and P1, respectively. This data demonstrated that capA was overexpressed successfully in P1.

To evaluate the expression level of capA in P1-capA, RT-qPCR assay was performed with 16S rRNA gene as an internal reference gene. As shown in Fig. 2B, the expression of capA in P1-capA is significantly higher than that in P1. The result showed that the recombinant strain promotes the expression of $c a p A$, which will increase the production of CPS.

\section{CPS Yield Evaluation}

To analyze the correlation of growth of P1 and P1-capA strains and the production of CPS in them, the growth curve at $\mathrm{OD}_{600}$ with CPS production was tested. As shown in Fig. 3A, the production of CPS has an obvious

A

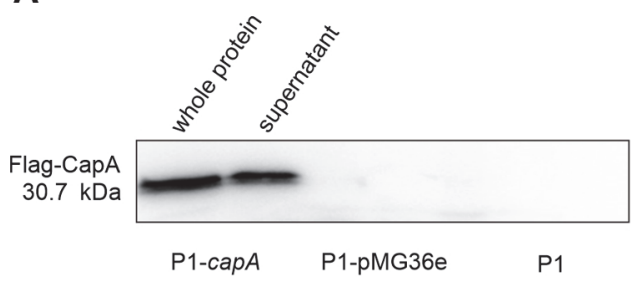

B

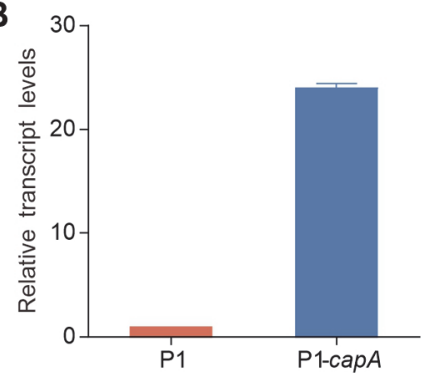

Fig. 2. Validation of $\boldsymbol{c a p A}$ overexpression. (A) Western blot analysis of CapA in recombinant bacteria; P1 without the plasmid and P1 with the original plasmid pMG36e were used as controls. (B) Analysis of capA gene overexpression at transcriptional level.
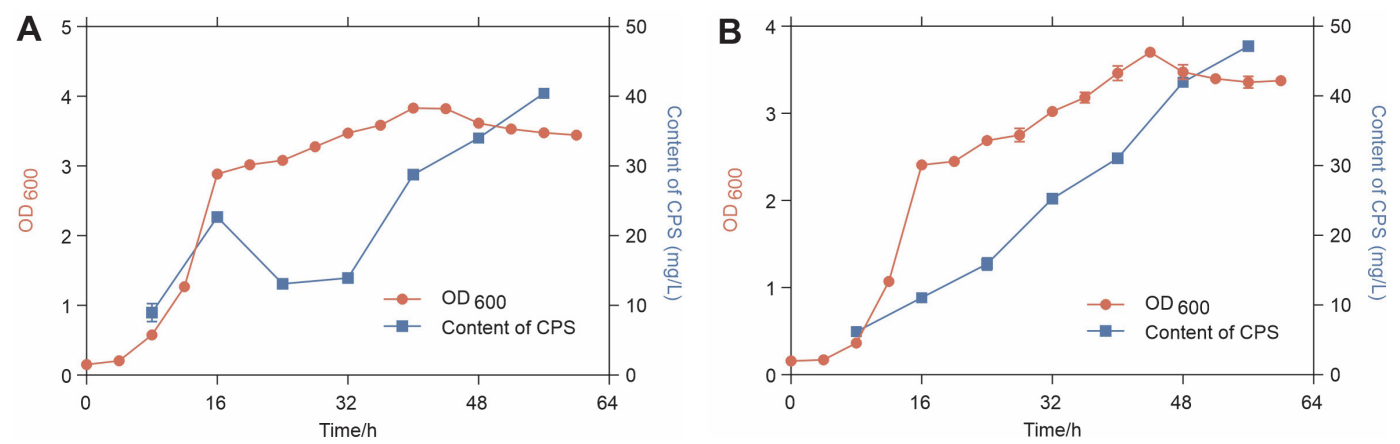

Fig. 3. Evaluation of strain growth and CPS production in P1 (A) and P1-capA (B). 
A

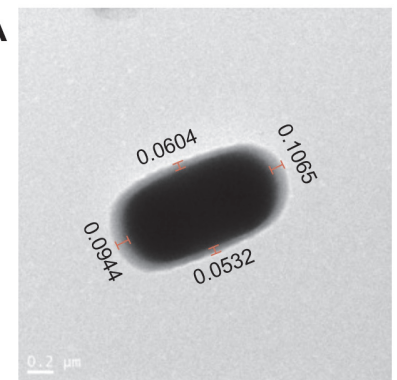

B

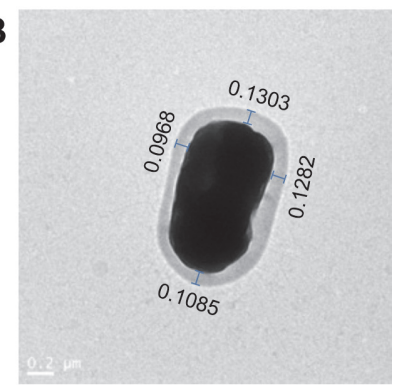

Fig. 4. Transmission electron microscopy for illustration of EPSs in P1 (A) and P1-capA (B). The numbers represent the thickness (micrometer) of capsular polysaccharide in P1 (A) and P1-capA (B).

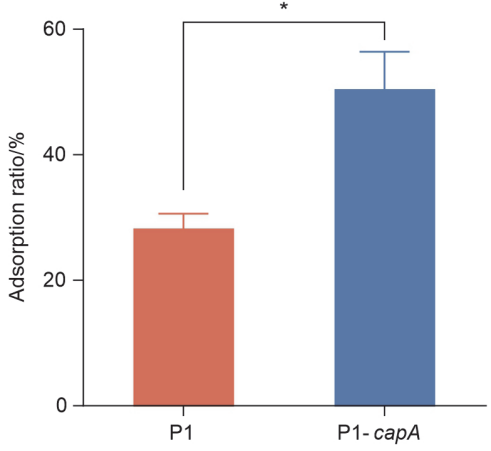

Fig. 5. DBP adsorption capacity of P1 and P1-capA. The experiments were duplicated three times and the data were presented with standard deviation. ${ }^{*} p<0.05$.

oscillation from $24 \mathrm{~h}$ to $32 \mathrm{~h}$ in $\mathrm{P} 1$ with growth time continuing. The production of CPS in P1-capA continuously increased (Fig. 3B). After $24 \mathrm{~h}$ cultivation, the yield of CPS of P1-capA was higher than that of P1, especially at the time point of $32 \mathrm{~h}$. The CPS production in P1-capA was higher than that in P1 by $11.3 \mathrm{mg} / \mathrm{l}$. Therefore, the growth time of $32 \mathrm{~h}$ was selected as the reference time point for further studies.

\section{Morphological Change of Strain}

Transmission electron microscopy (TEM) was used to observe the changes and differences of CPS in P1 and P1capA. The two strains were collected for TEM observation after $32 \mathrm{~h}$ of cultivation. As seen both in P1 (Fig. 4A) and P1-capA (Fig. 4B), the EPS thicknesses of P1 and P1-capA were in the range of $0.0786 \pm 0.0224$ and $0.1160 \pm$ $0.0480 \mu \mathrm{m}$ respectively. Although the EPSs were uneven around the cell, the EPS thickness of P1-capA was significantly higher than that of $\mathrm{P} 1$ in each of the same locations. This result indicated that the production of EPSs increased after capA overexpression in P1-capA.

\section{Comparison of DBP Adsorption Capacity}

LAB as a GRAS microorganism is widely used to adsorb and remove harmful substances such as zearalenone, acrylamide and heavy metals [37-39]. Here, we compared the DBP adsorption ratio of P1 and P1-capA after $32 \mathrm{~h}$ of cultivation. As shown in Fig. 5, the adsorption ratio of DBP in P1-capA with the overexpression of CapA protein was significantly higher than that in P1. It displayed that the CPS in both P1 and P1-capA could play roles in DBP adsorption, and the overexpression of CPS significantly enhanced the adsorption ratio to $50.48 \%$.

\section{Discussion}

EPSs are one of the main components of bacterial cell wall, and the biosynthesis of it can be affected by many factors from the genetic structure of bacteria to cultural conditions [40, 41]. To increase the production of EPSs, researchers have investigated various pathways to achieve this goal. For example, Midik et al. recently discussed the effect of different culture conditions (including temperature, $\mathrm{pH}$, and incubation time) on EPS production in lactic acid bacteria [42]. So far, the highest production of EPS in lactobacilli was reported as $2.775 \mathrm{~g} / \mathrm{l}$ in L. rhamnosus RW-9595 M [43], and the second highest production was $2.5 \mathrm{~g} / \mathrm{l}$ in L. kefiranofaciens WT-2B [44]. Here, we obtained $11.3 \mathrm{mg} / \mathrm{l}$ higher EPS production compared with the wild-type strain by overexpressing capA gene in $L$. plantarum $\mathrm{P} 1$. This provides a new strategy to enhance EPS production in LAB, which makes it possible for LAB strains to be used for the removal of toxic substances, such as DBP. In addition, we will further increase EPS production in LAB by screening starting strains, and optimizing culture conditions and fermentation parameters in the future. 
In recent years, many studies demonstrated that $\mathrm{LAB}$ strains were widely used to adsorb and eliminate harmful substances [45]. In previous work, we have evaluated the adsorption of DBP by LAB, and the data indicated that the P1 strain could effectively adsorb DBP [22]. In this study, we constructed an overexpression LAB strain, which indicated that CPS thickness of P1-capA was increased to $0.13 \mu \mathrm{m}$. Therefore, the absorption efficiency of DBP in P1-capA was significantly higher by $50.48 \%$ than that in P1. As comparison, a previous study indicated that the DBP absorption in Leuconostoc mesenteroides DM1-2 was 45.00\% [46]. In addition, the microbial elimination of DBP from the natural environment is the main goal and methodology. So far, many bacteria species were used to remove DBP from environment, in activated sludge [47, 48], soil $[49,50]$, and water $[51,52]$. These bacteria can efficiently remove DBP from the environment in vitro, but are not suitable for usage in vivo. Compared with those bacteria, LAB is safe for human beings and has more potential for DBP adsorption and removal in vivo. Furthermore, except for our previous works [22], Zhao et al., also engaged in the study of DBP removal using LAB from the point of chemical binding [53]. In the present study, we applied overexpression strategy using capA gene to enhance the production of CPS, and significantly increased the adsorption efficiency. This study provides a safe method for the adsorption and removal of DBP and further provides insight for the low-cost removal of environmental pollutants.

\section{Acknowledgments}

This work was supported by grants from the National Natural Science Foundation of China (31730004), and the General Program of Shanghai Natural Science Foundation (19ZR1413700).

\section{Reference}

1. Zajšek K, Goršek A, Kolar M. 2013. Cultivating conditions effects on kefiran production by the mixed culture of lactic acid bacteria imbedded within kefir grains. Food Chem. 139: 970-977.

2. Dilna SV, Surya H, Aswathy RG, Varsha KK, Sakthikumar DN, Pandey A, et al. 2015. Characterization of an exopolysaccharide with potential health-benefit properties from a probiotic Lactobacillus plantarum RJF4. LWT - Food Sci. Technol. 64: 1179-1186.

3. Mende S, Rohm H, Jaros D. 2016. Influence of exopolysaccharides on the structure, texture, stability and sensory properties of yoghurt and related products. Int. Dairy J. 52: 57-71.

4. Caggianiello G, Kleerebezem M, Spano G. 2016. Exopolysaccharides produced by lactic acid bacteria: from health-promoting benefits to stress tolerance mechanisms. Appl. Microbiol. Biotechnol. 100: 3877-3886.

5. Zhou Y, Cui Y, Qu X. 2019. Exopolysaccharides of lactic acid bacteria: Structure, bioactivity and associations: a review. Carbohydr. Polym. 207: 317-332.

6. Daisley BA, Monachese M, Trinder M, Bisanz JE, Chmiel JA, Burton JP, et al. 2019. Immobilization of cadmium and lead by Lactobacillus rhamnosus GR-1 mitigates apical-to-basolateral heavy metal translocation in a Caco-2 model of the intestinal epithelium. Gut Microbes 10: 321-333.

7. Ge N, Xu JJ, Peng BZ, Pan SY. 2017. Adsorption mechanism of tenuazonic acid using inactivated lactic acid bacteria. Food Control 82: $274-282$.

8. Ojekunle O, Banwo K, Sanni A. 2017. In vitro and in vivo evaluation of Weissella cibaria and Lactobacillus plantarum for their protective effect against cadmium and lead toxicities. Lett. Appl. Microbiol. 64: 379-385.

9. Liu C-T, Hsu IT, Chou C-C, Lo P-R, Yu R-C. 2009. Exopolysaccharide production of Lactobacillus salivarius BCRC 14759 and Bifidobacterium bifidum BCRC 14615. World J. Microbiol. Biotechnol. 25: 883-890.

10. Boels IC, Kleerebezem M, de Vos WM. 2003. Engineering of carbon distribution between glycolysis and sugar nucleotide biosynthesis in Lactococcus lactis. Appl. Environ. Microbiol. 69: 1129-1135.

11. Patel S, Majumder A, Goyal A. 2011. Potentials of exopolysaccharides from lactic acid bacteria. Ind. J. Microbiol. 52: 3-12.

12. Surayot U, Wang J, Seesuriyachan P, Kuntiya A, Tabarsa M, Lee Y, et al. 2014. Exopolysaccharides from lactic acid bacteria: structural analysis, molecular weight effect on immunomodulation. Int. J. Biol. Macromol. 68: 233-240.

13. Becker A. 2015. Challenges and perspectives in combinatorial assembly of novel exopolysaccharide biosynthesis pathways. Front. Microbiol. 6: 687

14. Yang Z, Li S, Zhang X, Zeng X, Li D, Zhao Y, et al. 2010. Capsular and slime-polysaccharide production by Lactobacillus rhamnosus JAAS8 isolated from Chinese sauerkraut: potential application in fermented milk products. J. Biosci. Bioeng. 110: 53-57.

15. Fontana C, Li S, Yang Z, Widmalm G. 2015. Structural studies of the exopolysaccharide from Lactobacillus plantarum C88 using NMR spectroscopy and the program CASPER. Carbohydr. Res. 402: 87-94.

16. Whitfield C, Paiment A. 2003. Biosynthesis and assembly of Group 1 capsular polysaccharides in Escherichia coli and related extracellular polysaccharides in other bacteria. Carbohydr. Res. 338: 2491-2502.

17. Fang HQ, Wang J, Lynch RA. 2017. Migration of di(2-ethylhexyl)phthalate (DEHP) and di-n-butylphthalate (DBP) from polypropylene food containers. Food Control 73: 1298-1302.

18. Albert O, Jegou B. 2014. A critical assessment of the endocrine susceptibility of the human testis to phthalates from fetal life to adulthood. Hum. Reprod. Update 20: 231-249.

19. Al-Gubory KH. 2014. Environmental pollutants and lifestyle factors induce oxidative stress and poor prenatal development. Reprod. Biomed. Online 29: 17-31.

20. Trasande L, Attina TM. 2015. Association of exposure to di-2-ethylhexylphthalate replacements with increased blood pressure in children and adolescents. Hypertension 66: 301-308.

21. Daiem MMA, Rivera-Utrilla J, Ocampo-Perez R, Mendez-Diaz JD, Sanchez-Polo M. 2012. Environmental impact of phthalic acid esters and their removal from water and sediments by different technologies - A review. J. Environ. Manage. 109: 164-178.

22. Shi X, Hu C, Cai S, Tao X, Zhou Y, Smidt H, et al. 2020. Protective effects of Lactobacillus plantarum strain P1 against toxicity of the environmental oestrogen di-n-butyl phthalate in rats. Benef. Microbes. 11: 803-813.

23. van de Guchte M, van der Vossen JM, Kok J, Venema G. 1989. Construction of a lactococcal expression vector: expression of hen egg white lysozyme in Lactococcus lactis subsp. lactis. Appl. Environ. Microbiol. 55: 224-228.

24. Gu XX, Tan JX, Tian HT, Zhang YL, Luo YB, Guo XH. 2014. Construction of a food-grade expression vector based on pMG36e by using an $\alpha$-galactosidase gene as a selectable marker. J. Int. Agric. 13: 1802-1808.

25. van de Guchte M, Kodde J, van der Vossen JM, Kok J, Venema G. 1990. Heterologous gene expression in Lactococcus lactis subsp. lactis: synthesis, secretion, and processing of the Bacillus subtilis neutral protease. Appl. Environ. Microbiol. 56: 2606

26. McAuliffe O, Hill C, Ross R. 2000. Identification and overexpression of ltnI, a novel gene which confers immunity to the twocomponent lantibiotic lacticin 3147. Microbiology 146 (Pt 1): 129-138. 
27. Raha AR, Chang LY, Sipat A, Yusoff K, Haryanti T. 2006. Expression of a thermostable xylanase gene from Bacillus coagulans ST-6 in Lactococcus lactis. Lett. Appl. Mcrobiol. 42: 210-214.

28. Wang C, Zhang C-W, Liu H-C, Yu Q, Pei X-F. 2008. Non-fusion and fusion expression of $\beta$-galactosidase from Lactobacillus bulgaricus in Lactococcus lactis. Biomed. Environ. Sci. 21: 389-397.

29. Labrie S, Bart C, Vadeboncoeur C, Moineau S. 2005. Use of an a-galactosidase gene as a food-grade selection marker for Streptococcus thermophilus. J. Dairy Sci. 88: 2341-2347.

30. Sridhar VR, Smeianov VV, Steele JL. 2006. Construction and evaluation of food-grade vectors for Lactococcus lactis using aspartate aminotransferase and $\alpha$-galactosidase as selectable markers. J. Appl. Microbiol. 101: 161-171.

31. Ciszek-Lenda M, Nowak B, Śróttek M, Gamian A, Marcinkiewicz J. 2011. Immunoregulatory potential of exopolysaccharide from Lactobacillus rhamnosus KL37. Effects on the production of inflammatory mediators by mouse macrophages. Int. J. Exp. Pathol. 92: 382-391.

32. Lebeer S, Claes IJJ, Verhoeven TLA, Vanderleyden J, De Keersmaecker SCJ. 2011. Exopolysaccharides of Lactobacillus rhamnosus GG form a protective shield against innate immune factors in the intestine. Microb. Biotechnol. 4: 368-374.

33. Bringel F, Hubert J-C. 1990. Optimized transformation by electroporation of Lactobacillus plantarum strains with plasmid vectors. Appl. Microbiol. Biotechnol. 33: 664-670.

34. Schmittgen T, Livak K. 2008. Analyzing real-time PCR data by the comparative C(T) method. Nat. Protocols 3: 1101-1108.

35. Rühmann B, Schmid J, Sieber V. 2015. Methods to identify the unexplored diversity of microbial exopolysaccharides. Front. Microbiol. 6: 565-565.

36. Polak-Berecka M, Waśko A, Skrzypek H, Kreft A. 2013. Production of exopolysaccharides by a probiotic strain of Lactobacillus rhamnosus: Biosynthesis and purification methods. Acta Alimentaria 42: 220-228.

37. Vega MF, Dieguez SN, Riccio B, Aranguren S, Giordano A, Denzoin L, et al. 2017. Zearalenone adsorption capacity of lactic acid bacteria isolated from pigs. Braz. J. Microbiol. 48: 715-723.

38. Shen Y, Zhao SJ, Zhao XD, Sun HY, Shao ML, Xu HH. 2019. In vitro adsorption mechanism of acrylamide by lactic acid bacteria. LWT-Food Sci. Technol. 100: 119-125.

39. Lin DR, Cao HF, Zhong YX, Huang YC, Zou JP, He Q, et al. 2019. Screening and identification of Lactic acid bacteria from Ya'an pickle water to effectively remove $\mathrm{Pb}^{2+}$. AMB Express. 9: 10 .

40. Ciszek-Lenda M, Nowak B, Srottek M, Gamian A, Marcinkiewicz J. 2011. Immunoregulatory potential of exopolysaccharide from Lactobacillus rhamnosus KL37: effects on the production of inflammatory mediators by mouse macrophages. Int. J. Exp. Pathol. 92: 382-391.

41. Lebeer S, Claes IJ, Verhoeven TL, Vanderleyden J, De Keersmaecker SC. 2011. Exopolysaccharides of Lactobacillus rhamnosus GG form a protective shield against innate immune factors in the intestine. Microb. Biotechnol. 4: 368-374.

42. Midık F, Tokatlı M, Elmacı SB, Özçelik F. 2020. Influence of different culture conditions on exopolysaccharide production by indigenous lactic acid bacteria isolated from pickles. Arch. Microbiol. 202: 875-885.

43. Macedo M, Lacroix C, Gardner N, Champagne C. 2002. Effect of medium supplementation on exopolysaccharide production by Lactobacillus rhamnosus RW-9595M in whey permeate. Int. Dairy J. 12: 419-426.

44. Maeda H, Zhu X, Suzuki S, Suzuki K, Kitamura S. 2004. Structural characterization and biological activities of an exopolysaccharide kefiran produced by Lactobacillus kefiranofaciens WT-2BT. J. Aric. Food Chem. 52: 5533-5538.

45. Zhao HF, Zhou F, Qi YQ, Dziugan P, Bai FL, Walczak P, et al. 2013. Screening of Lactobacillus strains for their ability to bind Benzo(a)pyrene and the mechanism of the process. Food Chem. Toxicol. 59: 67-71.

46. Lili Z, Hongfei Z, Shoukat S, Xiaochen Z, Bolin Z. 2017. Screening lactic acid bacteria strains with ability to bind di-n-butyl phthalate via Turbiscan technique. Antonie Van Leeuwenhoek 110: 759-769.

47. Hu J, Yang Q, Wang JL. 2015. Biodegradation of di-n-butyl phthalate in sequencing batch reactor bioaugmented with Micrococcus sp. and the bacterial community analysis. Int. J. Environ. Sci. Technol. 12: 2819-2828.

48. He Z, Niu C, Lu Z. 2014. Individual or synchronous biodegradation of di-n-butyl phthalate and phenol by Rhodococcus ruber strain DP-2. J. Hazard. Mater. 273: 104-109.

49. Chen XJ, Birk C, Song CM. 2015. Time-domain analysis of wave propagation in 3-D unbounded domains by the scaled boundary finite element method. Soil Dyn. Earthq. Eng. 75: 171-182.

50. Jin L, Sun X, Zhang X, Guo Y, Shi H. 2014. Co-metabolic biodegradation of DBP by Paenibacillus sp. S-3 and H-2. Curr. Microbiol. 68: $708-716$.

51. Feng CC, Zhang Y, Wang L, Li XQ, Chen YY, Qu JH, et al. 2020. Uptake mechanism of di-n-butyl phthalate by Novosphingobium species DNB-S3. Int. Biodeter. Biodegr. 148: 104910

52. Yang CF, Wang CC, Chen CH. 2014. Di-n-butyl phthalate removal by strain Deinococcus sp R5 in batch reactors. Int. Biodeter. Biodegr. 95: 55-60.

53. Zhao LL, Pan X, Yang QX, Zhao RX, Li XL. 2020. The ability of lactic acid bacteria strains to remove di-n-butyl phthalate in simulated food matrices. Int. J. Food Sci. Technol. 56: 553-562. 